\title{
Kliniğimizde tedavileri yapılan baş ve boyun schwannomlu olgular
}

\author{
Evaluation of the head and neck schwannoma's in our clinic \\ Emine Elif Altuntaş*, Adem Bora, Yavuz Sultan Selim Cerrah, Suphi Müderris, \\ Şahande Elagöz
}

Kulak Burun Boğaz Anabilim Dalı (Yrd. Doç. Dr. E. E. Altuntaş, Dr. A. Bora, Dr. Y. S. S. Cerrah, Prof. Dr. S. Müderris), Patoloji Anabilim Dalı (Prof. Dr. Ş. Elagöz), Cumhuriyet Üniversitesi Tıp Fakültesi, TR-58140 Sivas

\begin{abstract}
Özet
Amaç. Schwannomlar (neurilemmomlar) periferik, kranial ve otonomik sinirlerin kılıflarından kaynaklanan; çoğunluğu baş boyun bölgesinde olmak üzere vücudun her yerinde görülebilen nadir, soliter nörojenik tümörlerdir. Klinik olarak büyüme hızları yavaş olan bu tümörler sıklıkla boyunda asemptomatik kitleler olarak karşımıza çıkar. Yöntem. Bu çalışmada kliniğimizde 20042008 yılları arasında cerrahi eksizyon uygulanmış ve histopatoljik olarak benign schwannom tanısı konulmuş altı olgu retrospektif olarak literatür eşliğinde incelenmiştir. Bulgular. Tümoral kitle olguların; ikisinde lateroservikal, birinde parafarengeal, birinde premaksiller bölgede; birinde timpaniumda ve birinde de sert damakta lokalize idi. Kitlelerin nöronal kökeninin kaynağ 1 incelendiğinde olguların; birinde servikal sempatik zincir, birinde inferior orbital sinir ve birinde de timpanik sinir olduğu tespit edildi. Olguların tümünde cerrahi eksizyon sırasında sinir fonksiyonları tam olarak korunmuş olup; sinir greftlenmesine gereksinim duyulmamıştır. Sadece infraorbitalsininden köken alan bir olguda postoperatif yüzde parestezi gelişmiştir. Sonuç. Bu çalışmada baş boyun bölgesindeki schwannomların tanısı, patolojik özellikleri, prognozları ve tedavi yaklaşımlarıtartışılmıştır.
\end{abstract}

Anahtar sözcükler: Nörofibromatozis 2, baş ve boyun tümörleri, tanı, klinik protokolleri

\begin{abstract}
Aim. Schwannomas (neurilemmomas) are solitary rare neurogenic tumors that originae from the sheath of peripheral, cranial or autonomic nerve cells. Schwannomas can be seen everywhere in he body but more-often they are located at the head and neck region. They grow slowly clinically and frequently manifest themselves as asymptomatic masses in the neck. Method. In this retrospectively study, six patients who suffer from benign schwannoma have been histopathologically diagnosed and operated in our clinic between 2004 and 2008. Results. Head and neck mass of these six patients were located at the laterocervical region in two patients.and and at the parapharyngeal region, tympanium, premaxillary region and hard palate in the remaining four patients respectively. The neural origins of the masses were cervical sympathetic chain in one, inferior orbital nerve in one and nnervus tympanicus in another. The functions of the nerves were fully preserved during surgical excision of these six cases via conservative approaches, thus no nerve grafting was needed. Only in one case facial paresthesia that originated from the infraorbital nerve developed postoperatively. one of the mass which was Conclusion. In this study the diagnosis, pathological characteristics, treatment and prognosis of head and neck schwannoma is discussed.
\end{abstract}

Keywords: Neurofibromatosis 2, head and neck neoplasms, diagnosis, clinical protocols

Geliş tarihi/Received: 06 Şubat 2012; Kabul tarihi/Accepted: 02 Ağustos 2012

\section{*İletişim adresi:}

Dr. Emine Elif Altuntaş, Kulak Burun Boğaz Anabilim Dalı, Cumhuriyet Üniversitesi Tıp Fakültesi Sivas. E-posta: ealtunta@yahoo.com 


\section{Giriş}

Schwannomlar benign, genellikle soliter, enkapsüle, periferik sinir kılıflarının schwann hücrelerinden köken alan tümörlerdir. Schwann hücre kılıfı ile kaplı kranial sinirlerden köken aldıklarından optik ve olfaktör sinir dışındaki tüm kranial sinirlerden gelişebilirler; en sık köken aldıkları kranial sinir vestibulocochlearis'dir ve diğer kranial sinirlerin tutulumları ise son derece nadirdir. Vagus orijinli schwannomlar nadir görülen tümörlerdir; yavaş gelişim göstermeleri nedeniyle geç semptom verirler ve klinik tanıları zor konur [1-3]. Nörilemmoma, nörinom, perinöral fibroblastom, periferal gliom gibi değişik isimlerle de adlandırılan bu klinik tablo patolojik olarak ilk defa 1908 yılında Verocay tarafından tarif edilmiştir. Schwannomlar'ın \%25-40'1 baş boyun bölgesinde yerleşim gösterir [4-6]. Nörilemmoma'lar lokalizasyon ve kaynaklandıkları sinire göre iki gruba ayrılır; son dört kranial sinirden köken alan parafarengeal schwannomlar medial grubu, servikal ve brakial pleksustan kaynaklanan servikal sempatik zincir schwannomları ise lateral grubu oluşturur [4]. Bu tümörler baş ve boyun bölgesinin yumuşak doku tümörleri içerisinde yer almakla birlikte farklı klinik seyirleri ve karakteristik özellikleri nedeniyle ayrı bir grupta değerlendirilmeleri gereklidir [7].

$\mathrm{Bu}$ çalışmada cerrahi olarak çıkarılan ve histopatolojik olarak benign schwannom tanısı almış altı olgunun klinik seyri ve tedavi yaklaşımlarımız açısından literatür eşliğinde incelenmesi amaçlanmıştır.

\section{Gereç ve yöntem}

Bu çalışmada kliniğimizde 2004-2008 yılları arasında cerrahi eksizyon uygulanmış ve histopatolojik olarak benign schwannom tanısı konulmuş 6 olgunun retrospektif olarak klinik seyri ve tedavi yaklaşımlarımızın değerlendirilmesi sunuldu. Olgulara ait bilgilere arşivimizde yer alan dosyalardan ulaşıldı; bilgilerinin tümüne ulaşılamayan olgular çalışma dışı bırakıldı. Olguların tümüne operasyon öncesinde tanısal amaçlı kontrastlı bilgisayarlı tomografi (BT) çekilmiştir. Manyetik rezonans (MRG), doppler ultrasonografi (USG) ve anjiografi ayırıcı tanıda glomus tümörü veya kemodektoma düşünülen olgulara uygulanmıştır (Resim1). Olguların postoperatif dönemde ortalama takip süresi 24,3 aydır. Tüm olgular lezyonlarının lokalizasyonları, köken aldıkları sinirler, uygulanan cerrahi yaklaşımlar ve karşılaşılan komplikasyonlar yönünden değerlendirildi. Elde edilen bulguların kaydedilmesinde ve değerlendirilmesinde SPSS 16.0 programı (SPSS Inc., Chicago, IL, USA) kullanıld1. Oran olarak sunulan verilerin karşılaştırılmasında ki-kare testi kullanıldı.

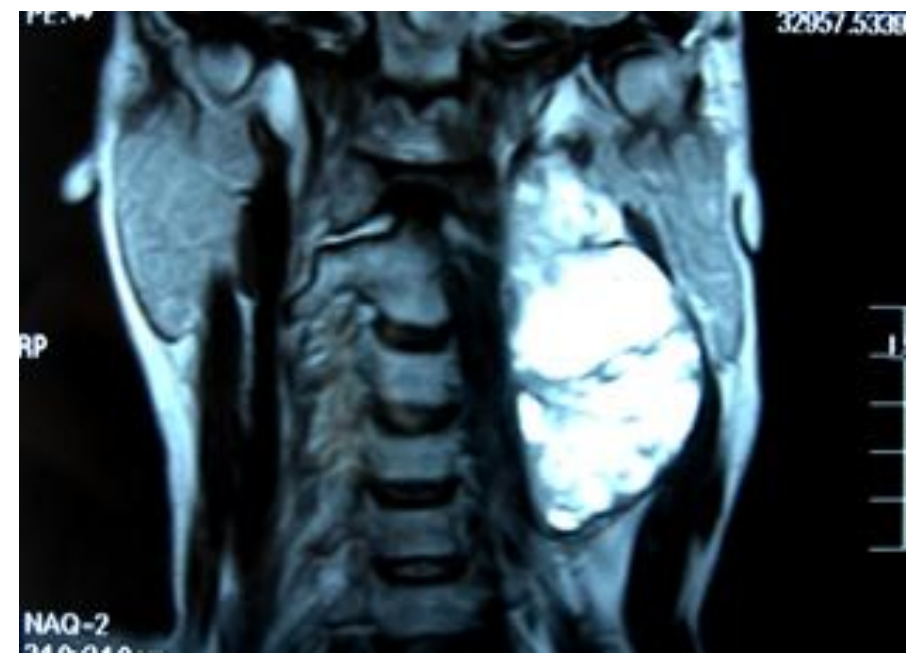

Resim 1. Koronal T2 ağırlıklı kesitte sol anterolateral paravertebral alanda SKM kasını laterale yaylandıran kistik dominanslı kistik-solit yapıda düzgün kontürlü kitle lezyonu. 


\section{Bulgular}

Olgunun üçü erkek, üçü kadın idi. Yaşları 14-63 (ortalama 46,8) arasında değişmekteydi. En sık kliniğe başvuru şikayeti boyunda ağrısız düzgün yüzeyli şişlik (\%50) ve baş ağrısı (\%50) idi (Tablo 1).

Tablo 1. Baş boyun schwannomlu olgularımızın doktora ilk başvuru şikayetleri.

\begin{tabular}{ll}
\hline Semptom & Sayı \\
\hline Boyunda kitle & 3 \\
Ağız içinde şişlik & 1 \\
Kulakta çınlama & 1 \\
Yanakta şişlik & 1 \\
Baş ağrısı & 3 \\
\hline
\end{tabular}

Boyun kitleleri olguların; ikisinde $(\% 33,3)$ lateroservikal bölgede, birinde $(\% 16,6)$ parafarengeal bölgede, birinde $(\% 16,6)$ timpaniumda, birinde $(\% 16,6)$ premaksiller bölgede ve birinde de $(\% 16,6)$ sert damakta lokalize idi. Kitlelerin nöronal kökeninin kaynă̆ 1 değerlendirildiğinde olguların; birinde $(\% 16,6)$ servikal sempatik zincir, birinde $(\% 16,6)$ inferior orbital sinir ve birinde de $(\% 16,6)$ tympaniksinin olarak belirlendi diğer üçünde $(\% 50,2)$ ise nöronal kökeni belli değildi. Olguların hiçbirin de preoperatif dönemde tutulan kranial sinirin muayenesinde fonksiyon kaybı saptanmamıştır. Lezyonlarının lokalizasyonları, köken aldıkları sinirler, uygulanan cerrahi yaklaşımlar ve komplikasyonlar Tablo 2 de özetlenmiştir.

Tablo 2. Kliniğimizde tanısı konup tedavileri yapılan baş boyun schwannomlu olgunun lezyonlarının lokalizasyonları, köken aldıkları sinirler, uygulanan cerrahi yaklaşımlar ve karşılaşılan komplikasyonlar.

\begin{tabular}{llll}
\hline Lezyonun lokalizasyonu & Köken aldığı kranial sinir & Cerrahi yaklaşım & Komplikasyon \\
\hline Servikal & Servikal sempatik zincir & Transservikal & Yok \\
Servikal & Bilinmiyor & Transservikal & Yok \\
Parafarengeal bölge & Bilinmiyor & Transmandibuler & Yok \\
Maksiller sinüs & N.infraorbitalis & Transoral & Yüzde parestezi \\
Timpanium & N.tympanicus & Transmastoid & Yok \\
Ağı içi & Bilinmiyor & Transoral & Yok \\
\hline
\end{tabular}

Boyunda ve parafarengeal bölgede kitlesi olan 3(\%50) olguya pre-operatif dönemde tanısal amaçlı ince iğne aspirasyon sitolojisi (İ̈AS) yapıldı. Bir $(\% 16,6)$ olguda kitle timpanumda olduğundan histopatolojik inceleme için tanı ve tedavi amaçlı eksizyon yapıld1; ayrıca sert damak lokalizasyonunda kitlesi olan bir $(\% 16,6)$ olguya da insizyonel biyopsi uyguland. IİAS uygulanan üç olgunun hiçbirinde histopatolojik incelemelerinde schwannom için tipik olan spindle hücrelerine rastlanmamıştır. Olguların tümünde eksizyonel biyopsi sonrası çıkarılan kitlelerin histopatolojik incelemesinde schwannom için tipik olan fibröz kapsülle çevrilmiş iğsi hücrelerden oluşmuş hücresel alanlarla (Antoni A) birlikte kistik ve miksoid alanlar (Antoni B) tespit edildi. Uygulanacak cerrahi tedavinin seçiminde tümörün tüm sınırlarına ulaşma olanağı sağlayabilecek en konservatif yaklaşımı seçmek amaçlanmıştır; bu nedenle boyun ve parafarengeal bölge tümörlerine transservikal yaklaşım, timpanik kavitede ki tümöre transmastoid yaklaşım, sert damaktaki ve premaksiller sinüs bölgesindeki kitlelere ise transoral yaklaşım tercih edilmiştir. Postoperatif dönemde olgularımızda herhangi bir majör komplikasyon gözlenmemiştir; sadece infraorbital sinirden köken alan bir $(\% 16,6)$ olguda yüzde parestezi tarzında sinir fonksiyon defisiti izlenmiştir. 


\section{Tartışma}

Schwannomlar, Schwann hücrelerinden köken alan ağrısız, benign, soliter, kapsüllü ve iyi diferansiye, boyunda servikolateral bölgeye yerleşim gösteren, horizontal düzlemde hareketli vertikal düzlemde hareketsiz tümörlerdir. Schwannomlar solid, kistik veya fluktuan karakterde olabilirler. Schwann hücresi olmayan optik ve olifaktor sinirler hariç kranial sinirlerin Schwann hücrelerinden köken alırlar. Schwannomlar genel olarak köken aldıkları sinirin ya yanında ve ona yapışık ya da sinir tarafından çevrelenmiş bir şekilde bulunurlar [8-10]. Schwannomların \%25-40'ı baş-boyun bölgesinde yerleşir. Bu tümörler her yaşta görülebilse de 3. ve 5. dekatlar da pik yapar ve her iki cinsiyette de eşit oranda görülmekle birlikte Hood ve ark. [11]'nın yaptığı bir çalışmada daha çok erkeklerde; Toriumi ve ark. [12]'nın yaptığı çalışmada ise kadınlarda daha fazla görülebileceği savunulmuştur.

Bizim olgularımızda da genel literatür bilgileri ile uyumlu olarak her iki cinste eşit oranda schwannom görülmüştür, ancak olgu sayımız az olduğundan bu konuda kesin bir yorum yapmamızın uygun olmayacağı kanısındayız. Baş boyun shwannomlarının kliniğinde spesifik semptom ve bulgusu yoktur; genellikle tesadüfen boyun palpasyonu sirasinda ele gelen ve çok yavaş büyüyen ağrısız boyun kitlesi ile tanı konur. Kitle büyüdükçe lokalizasyonuna göre disfaji, öksürük, nadiren preoperatif Horner sendromu, dispne ve disfoni gibi bası semptomlara neden olabilir [6, 13]. Ayrıca büyük lezyonlar, başın sağasola çevrilmesiyle veya kitlenin palpe edilmesiyle ortaya çıkan spazmodik, nonprodüktif tarzda öksürüğe neden olabilirler [1]. Bazı olgularda tümörün distalinde parestezi ve radiküler ağrı şikâyeti de görülebilir [12]. Schwannom olgularında ağrı ve parestezi görüldüğünde malignite olasılığı mutlaka ekarte edilmelidir. Schwannomların bir diğer tipik klinik özelliği de nörolojik defisitlerdir; eğer tümör fasiyal sinire ulaşırsa fasiyal paraliziye, vagal siniri tutarsa ses kısıklığına ve sensorial sinirlere ulaşır ise ağrıya neden olabilir [14]. Bizim olgularımızın da en sık görülen semptomları boyunda şişlik ve baş ağrısı olmakla birlikte literatürde pek rastlamadığımız ağız içinde şişlik, kulakta çınlama ve yanakta şişlik gibi nadir yakınmaları da mevcuttu. Bu nedenle schwannomalı olgularda patolojinin köken aldığı sinire göre klinik semptomlarının çeşitlilik gösterebileceğinin unutulmaması gerektiği kanısındayız. Shwannom'un tanısında rutin kan testleri ve direk grafilerin yeri yoktur. USG ve kontrastlı BT ise tümörün lokalizasyonu ve çevre yapılarla olan ilişkisini belirlemede faydalıdır. Son zamanlarda MRG tekniği, BT den farklı olarak sinirin kaynağının belirlenmesindeki üstünlügünden dolayı Schwannom gibi yumuşak doku tümörlerinin tanısında en değerli görüntüleme yöntemi haline gelmiştir [6]. Sakao ve ark. [15]'nın servikal bölgeye lokalize 35 Schwannomlu olgu üzerinde yaptıkları çalışmada, 10'unun vagus, beşinin brakial pleksus, üçünün servikal sempatik zincir kökenli olduğunu, 17 olgunun ise hangi sinirden köken aldığının tespit edilemediğini bildirmişlerdir. $\mathrm{Bu}$ çalışmada ki altı olgunun nöronal kökeninin kaynağı; birinde $(\% 16,6)$ servikal sempatik zincir, birinde $(\% 16,6)$ inferior orbital sinir ve birinde de $(\% 16,6)$ n.tympanicus olarak belirlenirken diğer üç olgunun nöronal kökeni tespit edilememiştir. $\mathrm{Bu}$ olguların tümüne tanısal amaçlı öncelikle USG ve BT uygulanmış; ayırıcı tanı gereken ve sinir kaynağının belirlenmesi gereken üç olguya ise preoperatif dönemde MRI ile değerlendirme yapılmıştır. Schwannomalı olguların lenfadenopati, paraganglioma, brakial kist, minör tükrük bezi tümörleri, lipom, karotid arter anevrizması, 9-10-11-12. kranial sinirlere ait nörojenik kökenli tümörler, parotis derin lob tümörleri, teratoma, rabdomiyom ve menejiomlardan ayırıcı tanısının yapılması gerekir [16]. Schwannomların kesin tanısı histopatolojik inceleme ile konur. Tipik histopatolojik özelliği Antoni A ve Antoni B hücre alanları ile birlikte Verocay cisimlerinin görülmesidir. Bazen tümör tip A ve tip B'nin demarkasyon hattıyla birbirinden ayrıldı ğı mikst tipte de olabilir [1, 17, 18]. Servikal sempatik sinir Schwannomlarının tanısında preoperatif dönemde yapılan İIAS düşük pozitif sonuç vermesi nedeniyle tanıda ki yeri tartışmalıdır. Literatürdeki olguların çok azında pozitif aspirasyon sitolojisi rapor edilmektedir. Arıkan ve ark. [7]'nın başboyun bölgesine lokalize beş schwannomlu olgu üzerinde yaptıkları çalışmada preoperatif dönemde İİAS ile bu olguların hiç birine tanı koyamadıklarını; aspirasyon sitolojisinin 
boyunda ya da parafaringeal bölgede kitlesi olan olgularda ayırıcı tanı için preoperatif dönemde yapılması gerektiğini vurgulamışlardır. Bu çalışmadaki altı olgunun üçüne de İİAS yapılmış olup hiç birine preoperatif tanı konulamamıştır, bizde Arıkan ve ark. [7]'ları gibi bu hastaların ayırıcı tanısı için mutlaka preoperatif dönemde İIAS yapılması gerektiği kanısındayız. Schwannomlar nörofibromların aksine nadiren malign transformasyon gösterirler ve radyorezistan olduklarından radyoterapinin tedavide yeri yoktur. Lenfatik yayılım ve metastaz çok nadir görülür [7, 19]. Bu olguların esas tedavisi cerrahidir. Cerrahide primer amaç siniri koruyarak disseksiyonun gerçekleştirilmesidir; ancak bu tümörün lokalizasyonu, büyüklüğü, nekroz ve frajilite nedeniyle her zaman mümkün olamayabilir. Bu olgularda kitlenin sinirden diseksiyonu daha az kanlanan kapsül ile sinir arasındaki bölgeden yapılmalıdır. Literatürde kimi yazarlar intra kapsüler enükleasyon uygulamaktadır ancak bizim tercihimiz bu olgularda onkolojik açıdan daha uygun bir cerrahi yaklaşım olması, nüks riskinin daha az olması ve sinir fonksiyon kayıplarına daha az yol açması nedeniyle ekstrakapsüler eksizyon uygulanmasıdır [7, 20]. Siniri korumak mümkün olmuyorsa tümörün sinir ile birlikte rezeksiyonunu takiben uçuca anastamoz veya sinir grefti transpozisyonu gibi mikrocerrahi yöntemleri uygulanabilinir böylelikle disfoni ve aspirasyon gibi fonksiyon kaybını engellemek mümkün olabilmektedir. $\mathrm{Bu}$ amaçla literatürde en çok yapılan uygulama $\mathrm{n}$. vagus rekonstrüksiyonu için $\mathrm{n}$. aurikularis magnusdan elde edilen sinir greftinin kullanılmasıdır [1]. Lateral rinotomi, midfasiyal degloving, median thyrotomy ve trans servikal yaklaşım en sık uygulanan eksternal cerrahi yaklaşımlardır. Schwannomlar da total eksizyon sonrası nadiren rekürrens görülür [10]. Boyun ve parafarengeal Schwannom eksizyonu sonrası görülen en sık komplikasyon Horner sendromudur [5, 12]. Bu sendrom pitozis, myozis, enoftalmus ve ipsilateral anhidrozisten oluşmaktadır. Operasyon esnasında sinirde kesi oluşmamışsa spontan düzelme ihtimali yüksektir.

Sonuç olarak, baş boyun bölgesinde görülen Schwannomların bening tümörler olmakla beraber yeterli eksizyon yapılmadığı durumlarda aylar ya da yıllar içerisinde lokal nükslerin gösterebilecekleri unutulmamalıdır. Bu nedenle Schwannomlu olguların düzenli takiplerinin yapılması nükslerin erken dönemde takiplerinin yapılarak nöronal defisite yol açmadan tedavi edilebilmeleri açısından çok önemlidir. Ayrıca bu olgular eksizyon sonrasında gelişme ihtimali olan nörolojik fonksiyon kayıları ile ilgili olarak preoperatif dönemde mutlaka bilgilendirilmelidirler.

\section{Kaynaklar}

1. Anadolu Y, Tatlıpınar AU, Gerçeker M, Aytaç S. Servikal vagustan köken alan kistik schwannoma. K.B.B. ve BBC Dergisi 2001; pp: 121-4.

2. Stout AP. Tumors of the peripheral nervous system. J Missouri state med assoc $1949 ; 46 ; 255-9$.

3. Kriakos M. Pathology of selecred soft tissue tumors of the head and neck. Tumors of the Head and Neck: Clinical and pathological considerations'da. Ed. Batsakis JG. 2. bask1. Baltimore, William\&Wilkins 1979: 1254-6.

4. Diaz DD, Kennedy KS, Parker GS, White VJ. Schwannoma of the submandibular gland. Head Neck 1991; 13: 239-42.

5. Hornick P, John LC, Murray A, Davis S, Croft RJ, Lumley JS. Neurilemmoma as a cause of combined thoracic outlet and Horner's syndrome. Thorac cardiovasc Surg 1991; 39: 232-3.

6. Park CS, Suh KW, Kim CK. Neurilemmomas of the cervical vagus nerve. Head Neck 1991; 13: 439-41.

7. Arıkan OK, Tuna EÜ, Koç C, Özdem C. Baş ve Boyun schwannomları. Türk Otolarengoloji Arşivi 2002; 40: 30-5.

8. Chang SC, Schi YM. Neurilemmoma of the vagus nerve. A case report and brief literature review. Laryngoscope 1984; 94: 946-9.

9. Mukherjee DK. Neurilemmoma of the Vagus Nerve: A Case Report. J Laryngol otol 1979; 93: 187-92. 
10.Zhang H, Cai C, Wang S, Liu H, Ye Y, Chen X. Extracranial head and neck schwannomas: a clinical analysis of 33 patients. Laryngoscope 2007; 117: 27881.

11.Hood RJ, Reibel JF, Jensen ME, Levine PA. Schwannoma of the cervical sympathetic chain. The Virginia experience. Ann Otol Rhinol Laryngol 2000; 109: 48-51.

12.Toriumi DM, Atiyah RA, Murad T, Sisson GA Sr. Extracranial neurogenic tumors of the head and neck. Otolaryngol Clin North Am 1986; 19: 609-17.

13.Batsakis JG. Tumors of the peripheral nerveus system. Tumors of the Head and Neck 'de. Ed. Batsakis JG.4.Bask1. Baltimore, Williams\&Wilkins 1974; 231-49.

14.Rosen FS, Pou AM, Quinn FB Jr. Obstructive supraglottic schwannoma: a case report and review of the literature. Laryngoscope 2002; 112: 997-1002.

15.Sakao T, Noguchi S, Murakami N, Uchino S. Neurilemmoma of the neck; a report of 35 cases. Nihon Geka Gakkai Zasshi 1990; 91: 407-10.

16.Cabbarpur C, Büyüklü F, Çakmak Ö, Öztop İ, Özlüoğlu LN. Servikal sempatik zincirden kaynaklanan schwannom: Vaka Takdimi. Türk Otolarengoloji Arflivi 2002; 40: 153-6.

17. Hawkins DB, Luxford WM. Schwannomas of the head and neck in children. Laryngoscope 1980; 90: 1921-6.

18.Cohen LM, Schwartz AM, Rockoff SD. Benign Schwannomas: Pathologic Basis for CT Inhomogeneities. AJR Am J Roentgenol 1986; 147: 141-3.

19.Colreavy MP, Lacy PD, Hughes J, Bouchier-Hayes D, Brennan P, O'Dwyer AJ, Donnelly MJ, Gaffney R, Maguire A, O'Dwyer TP, Timon CV, Walsh MA .Head and neck schwannomas--a 10 year review. J Laryngol Otol 2000; 114: $119-24$.

20.Çelikkanat MS, Pata YS, Turgut S, Dağlı Ş, Doğan H, Özdem C. Nervus accessorius schwannomu. KBB ve Baş Boyun Cerrahisi Dergisi 1996; 4: 184-6. 